\title{
A Process for Developing Introductory Science Laboratory Learning Goals To Enhance Student Learning and Instructional Alignment
}

\author{
Jennifer M. Duis, ${ }^{*}{ }^{\dagger}, \S$ Laurel L. Schafer, ${ }^{\ddagger}$ Sophia Nussbaum, ${ }^{\ddagger}$ and Jaclyn J. Stewart ${ }^{\ddagger}$ \\ ${ }^{\dagger}$ Department of Chemistry and Biochemistry, Northern Arizona University, Flagstaff, Arizona 86011-5698, United States \\ ${ }^{\star}$ Department of Chemistry, University of British Columbia, Vancouver, BC V6T 1Z1, Canada
}

\section{Supporting Information}

ABSTRACT: Learning goal (LG) identification can greatly inform curriculum, teaching, and evaluation practices. The complex laboratory course setting, however, presents unique obstacles in developing appropriate LGs. For example, in addition to the large quantity and variety of content supported in the general chemistry laboratory program, the interests of faculty members from various chemistry subdisciplines and the service goals of such a course should be addressed. To optimize the instructional impact of limited laboratory contact time, achieve learning gains in basic and transferable (i.e., valuable in other sciences) laboratory learning content, and establish departmental consensus, a model was created for LG and assessment development that was inspired by interdisciplinary science laboratory LGs implemented at Rice University. These newly developed processes and materials were used to enhance the introductory chemistry laboratory curriculum at the University of British Columbia, involving a large ( $>1700$ student)

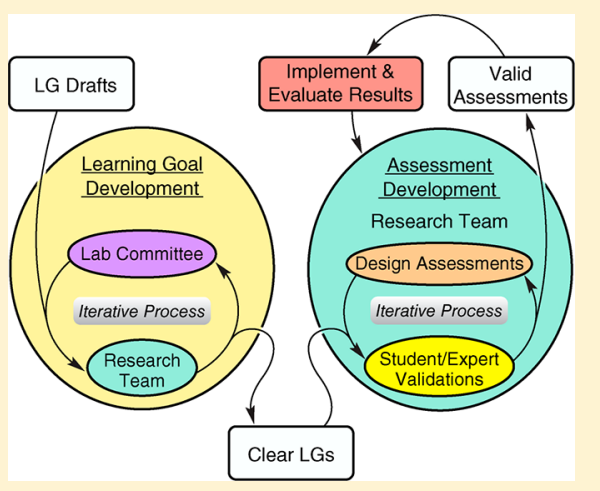
laboratory program. This model has potential to guide alignment and build consensus within, and possibly across, science laboratory instructional programs.

KEYWORDS: Laboratory Instruction, First-Year Undergraduate/General, Testing/Assessment, Chemical Education Research

FEATURE: Chemical Education Research

\section{INTRODUCTION}

Several educators assert that when students know course expectations through clearly communicated learning goals (LGs) or outcomes, the quality of learning will improve. ${ }^{1-8}$ Similarly, various writers suggest that LG development can substantively inform curriculum design and instructional and assessment practices. ${ }^{2,9-13}$ Furthermore, instructional departments are increasingly required to provide statements of LGs for their courses and curriculum. ${ }^{11}$ However, introductory science laboratory courses present unique challenges for LG development for a variety of reasons. These challenges include, but are not limited to:

Physical and temporal limitations of available laboratory space and the activities it was intended to support, which may prevent a "zero-based" design approach to LG development

The large quantity and variety of content typically found within a chemistry laboratory program, introductory or otherwise $^{14}$

The realization that few students taking the introductory laboratory course will become majors within that department

The potential interest of faculty from departmental subdisciplines and upper-level laboratory courses as to what students should learn in introductory courses
Learning goals, sometimes termed learning outcomes or performance objectives, are explicit statements about abilities, attitudes, skills, and knowledge that should be acquired by a student through completion of some instructional event. These events can be as small as a single lecture or laboratory session or as large as a complete course or departmental program. These statements provide clear expectations both for learner and instructor. A course syllabus, by contrast, typically enumerates chapter headings or a topical list to be studied. The expectations behind a list of topics are unclear to students and are often interpreted in many ways by different instructors, even within a single multisection course. For example, a laboratory syllabus might specify, "Keep a laboratory notebook", while a laboratory LG would direct students to "Maintain an up-to-date laboratory record (including proper documentation of outside resources) which is of sufficient detail that others could repeat any of your experiments if necessary". 15

In addition, learning may be enhanced when the goals, learning activities, and assessments are aligned. ${ }^{16}$ Achieving this alignment is a benefit of using the "backward design" curriculum development method, in which learning activities and assessments are chosen after the learning goals have been articulated. ${ }^{17}$ There is evidence that students perform better on

Published: August 28, 2013 


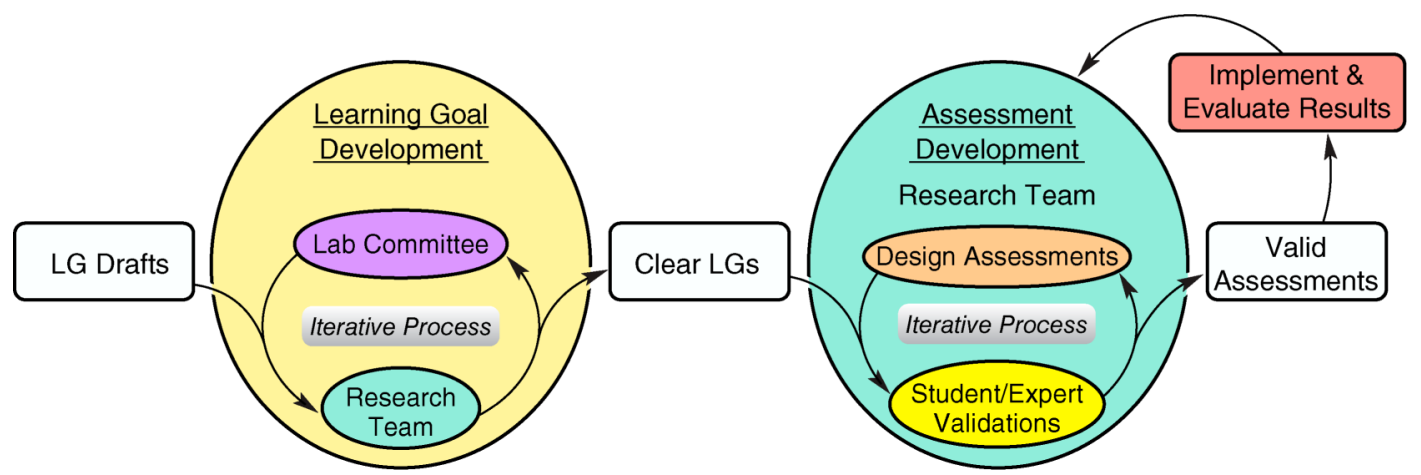

Figure 1. Model for development of learning goals and assessments of student learning goal attainment.

assessment items that tap into stated learning goals than items that are not associated with a learning goal, ${ }^{18}$ likely because students base their learning strategies on the goals. ${ }^{19}$ Furthermore, if the cognitive level, topic, criterion, or condition of a goal is misaligned with assessments, learners may approach studying in ways that hinder their success on assessments. Additionally, tools that assess the alignment of goals with assessments have been created to inform instructional design and ultimately reduce learner frustration that misalignment can cause. $^{20}$

To optimize instructional use of limited laboratory contact hours, help students achieve learning gains in basic (e.g., maintaining a laboratory notebook, selecting measurement tools with appropriate precision, and completing "common" techniques properly) and transferable (i.e., valuable in other sciences) laboratory learning content, and cultivate departmental consensus, a small research and development team was formed. This team consisted of an instructional research coordinator, the course instructor, a chemical education postdoctoral researcher, a science educator in the department, and two or three undergraduate researchers. In this paper, an LG and related student assessment development model for optimizing the introductory chemistry laboratory curriculum at the University of British Columbia (UBC), a large (>1700 student) program, developed by the authors is described. (Note: "Transferable" is not intended to invoke the educational psychology literature on "transfer".)

\section{SETTING}

This goal-based approach (reminiscent of the preconstructivist behavioral or performance objective movement) was developed and implemented to optimize the first-year chemistry laboratory course at UBC, and funded by the Carl Wieman Science Education Initiative. This laboratory course is taken by students who have completed Grade 12 chemistry (or the equivalent) and is mandatory for most Faculty of Science majors. Approximately 1700 students complete the full, twosemester course series and complete five, mixed-mode guidedinquiry style activities (supported by readings, technique guides, online tutorials, and virtual laboratories in off weeks) ${ }^{21}$ over each 13 -week semester.

\section{METHODS}

To confront unique challenges posed by introductory laboratory courses, these design decisions were made to address each of the challenges identified above:
Because the laboratory program is designed to accommodate existing activities, LGs were developed for current course materials.

The large quantity and variety of content in the current laboratory course (discipline-specific content, laboratory techniques, data recording and analysis skills, scientific processes, safe laboratory procedures, teamwork, etc.) were addressed by deciding that the first-year laboratory program should focus on "basic laboratory skills".

Recognizing that few students taking the introductory laboratory course will become chemistry majors, transferable (i.e., interdisciplinary) skills were emphasized.

The vested interests of faculty from all departmental subdisciplines was honored by inclusion of faculty from each subdiscipline and all laboratory instructors within the department on a departmental committee overseeing LG development.

\section{Learning Goal Development}

The forward-thinking science and engineering laboratory instructors at Rice University identified a set of program-wide learning objectives shared by all undergraduate teaching laboratories in natural sciences and engineering. ${ }^{2,23}$ This comprehensive framework for interdisciplinary science laboratory LGs was divided into five thematic areas:

1. Basic laboratory skills

2. Communication and record keeping

3. Maturity and responsibility

4. Context

5. Integration and application of knowledge/experience ${ }^{23}$

This framework provides a useful foundation upon which to build course-specific LGs that fit well within the service-course nature of introductory chemistry but also allow for extension into upper-division laboratory activities.

Learning goals were developed in this model by first tapping expertise of chemistry faculty members on the departmental committee overseeing LG development. After describing the above-cited five-part framework to the committee, several members examined current laboratory materials supporting each activity and prepared a draft of perceived LGs. Next, a chemistry education researcher synthesized the drafts of LGs for each activity. At this stage, prioritizing the basic and transferable laboratory skills helped generate a focused list of activity-specific LGs. In collaboration with the instructor who designed the course and members of the research and development team, the LGs were written in an active voice and integrated into the framework. Finally, through iterative discussions between the departmental committee and the 
research team, the LGs were refined until consensus was reached. (Note: The team strove for a list of LGs no longer than two pages for each activity; it is possible that even this length is too much to expect for a given laboratory activity.) With a set of agreed-upon LGs in hand, student assessments were designed and validated for measuring the attainment of these LGs. An iterative model for laboratory LG and assessment development is summarized in Figure 1.

\section{Learning Goal Development: Alignment and Articulation}

Challenges in developing consensus regarding laboratory LGs were identified. For example, two perceived LGs for a laboratory activity regarding vitamin $\mathrm{C}$ degradation, as assessed by iodometric titration of the changing vitamin $\mathrm{C}$ content in samples, included knowing the structure of vitamin $\mathrm{C}$ and the titration's chemical reactions. However, while the laboratory manual provides the structure of vitamin $C$ and its associated chemical reactions, this content is not aligned with the overall objective of optimizing learning of basic and transferable laboratory skills; thus, these particular perceived LGs were not selected for inclusion.

Another important challenge in LG development was unambiguous articulation. For example, consider the "titration technique" LG. Unfortunately, this simple phrase does not clearly communicate the intended laboratory skills packed within this important procedure. Thus, "titration technique" was rephrased as select glassware with the needed level of precision; proper volumetric glassware use and measurement reading; correct performance of titration techniques; list the steps of a titration; and manipulate data with basic calculations. In this manner, the intentions packed within "titration technique" were made clearer. Additionally, vague phrasing, verbs in particular, were edited to improve clear communication of desired student understanding, skills, and so on. For example, the vitamin $\mathrm{C}$ degradation activity included the goal, "understand and use a control". However, the verbs "understand" and "use" did not clearly convey what the student was expected to know and do. This statement was converted into an acceptable LG: describe the purpose of, design, and complete a laboratory activity with a suitable control. Furthermore, the "maintenance" of a laboratory notebook LG, described earlier, did not completely portray what was expected of students. This goal actually contains several subgoals that further clarify what students must include in their laboratory record: document laboratory procedures; record data and observations in an organized way; and "measure and report uncertain quantities with appropriate precision". ${ }^{23}$ By avoiding unclear verbs and phrases, these LGs can unambiguously express desired outcomes to learners and to other instructors.

Finally, with an agreed-upon list of consistently aligned and clearly articulated LGs, these LGs were organized into the chosen global framework. The first main section of the framework specified basic laboratory skills, which included: safety; laboratory procedures and techniques; laboratory records; data analysis; and laboratory procedure troubleshooting. Considering the vitamin $\mathrm{C}$ laboratory activity, both "iodometric titration" (subgoal: list the general procedural steps of a titration) and "set up a control" (subgoal: explain the purpose of a control) would be included as "basic laboratory skills," as illustrated in the LG excerpt shown in Figure 2.

\section{Assessment Development}

Once LGs for each laboratory activity had undergone the described development process, the assessment of these goals

\section{A. Basic Laboratory Skills}

A2. Perform common laboratory procedures correctly. When indicated, also be able to list general procedural steps and/or describe the purpose/use of the procedure.

\section{A2a. New laboratory procedures}

- Set up a control.

- Explain the purpose of a control and identify a control for a simple experiment.

- Perform iodometric titrations.

- List the general procedural steps of a titration.

Figure 2. Learning goal excerpt from a vitamin C laboratory activity.

was determined. First, current laboratory deliverables (quizzes, laboratory notebooks, report expectations, etc.) were reviewed to determine which LGs were already adequately assessed within the course's grading scheme. For the other LGs, appropriate assessment evidence (written, observation, tracking of online resource use, etc.) was identified. To optimize resources, LGs not captured by current laboratory deliverables were prioritized for assessment development. Prioritization was necessary because of the limited time available to add assessments during the laboratory period and that students would be asked to voluntarily complete these assessment "surveys" for course, not student, evaluation (further discussed in the following section and in the section Using Surveys as Course Assessments). Developed LG assessments were then validated with students and experts, as described in the Assessment Development: Validation section below.

\section{Assessment Development: Categorize, Prioritize, and} Prepare Instruments

Laboratory materials (student manual, laboratory quizzes, grading rubrics, etc.) for a particular laboratory activity were used to begin analysis of the activity's LGs. First, LGs that appear to be assessed by existing laboratory assignments were identified. Next, remaining LGs were placed in categories related to how student attainment of each LG could be assessed. Categorization was accomplished by highlighting each LG with a different color representing each category, or by placing LGs in a grid such as the example provided in Table 1.

Aspects of currently gathered and graded laboratory assignments often fit into additional categories (" $X$ " in Table 1) and it may be decided that current assignments need revision for closer alignment with identified LGs. However, it was argued that developing methods to document student attainment of LGs not yet assessed was a better use of resources in this initial work, particularly because current quizzes, notebooks, laboratory reports, and other means of students assessment were deemed of high to acceptable quality by the committee and research team.

LGs not monitored adequately by currently graded materials were prioritized for assessment development. Prioritization was needed, in part, to reduce "survey fatigue" that can threaten the quantity and quality of participation. ${ }^{24}$ Productive assessment development was also promoted by the iterative process used to define the LGs, illustrated in Figure 1. As noted previously, it was decided that basic laboratory skills, such as maintaining a laboratory notebook, selecting measurement tools delivering 
Table 1. Identifying Sources of Learning Goal Assessment Evidence

\begin{tabular}{|c|c|c|c|c|}
\hline Learning Goal & $\begin{array}{l}\text { Should } \\
\text { Be } \\
\text { Observed }\end{array}$ & $\begin{array}{l}\text { Can Be } \\
\text { in } \\
\text { Written } \\
\text { Form }\end{array}$ & $\begin{array}{l}\text { Can Be } \\
\text { Tracked } \\
\text { Online }\end{array}$ & $\begin{array}{c}\text { Part of } \\
\text { Currently } \\
\text { Gathered and } \\
\text { Graded } \\
\text { Materials }\end{array}$ \\
\hline $\begin{array}{l}\text { Perform an iodometric } \\
\text { titration }\end{array}$ & $\mathrm{X}$ & & & \\
\hline $\begin{array}{l}\text { List general procedural steps } \\
\text { of a titration }\end{array}$ & & $\mathrm{X}$ & & \\
\hline $\begin{array}{l}\text { Prepare data tables and } \\
\text { record results and } \\
\text { observations appropriately }\end{array}$ & & "X" & & $\mathrm{X}$ \\
\hline $\begin{array}{l}\text { Explain what data needs to } \\
\text { be recorded }\end{array}$ & & $\mathrm{X}$ & & \\
\hline $\begin{array}{l}\text { Complete the laboratory } \\
\text { activity calculations using } \\
\text { online tutorials and virtual } \\
\text { laboratory }\end{array}$ & & & $\mathrm{X}$ & \\
\hline
\end{tabular}

appropriate precision, and completing "common" techniques properly, were regarded as top priority in the first-year chemistry laboratory program. Titration skills, commonly taught in general chemistry laboratory courses, include many transferable and basic laboratory skills. For example, titration involves selecting devices capable of appropriate precision (a transferable skill), such as using a buret versus a graduated cylinder, and completing common laboratory techniques, such as correctly manipulating and reading a buret (a basic chemistry skill). Thus, assessments addressing the selection and use of a buret were identified. To assess correct procedures during titration (buret use), selected students were carefully observed and their performance monitored by a procedural rubric. The rubric was based on detailed procedural steps contained in the laboratory manual and further informed by observing students following those laboratory procedures. To assess another goal, students are able to list the general steps of a titration, survey questions were developed to assess students' knowledge of those techniques. Originally, these questions were open-ended, but it was quickly discovered that eliciting the desired level of detail was problematic. Thus, data gathered from open-ended questions and observations of student work in the laboratory were analyzed in developing multiple-choice and true-false assessment items to address aspects of titration technique frequently not conducted or described correctly. In a best-case scenario, however, development of suitable assessments is delayed until student observations and think-aloud interviews are completed and analyzed. This prevents many false starts and reduces the lost effort when a large portion of collected data must be set aside because the assessments did not reveal sought information.

\section{Assessment Development: Validation}

Assessments require validation to ensure students interpret questions as intended, and experts, namely experienced chemistry professors, agree on whether the assessment is congruent with the corresponding LG. Validation by experts from outside of the team improves construct ${ }^{25}$ and face validity (ref 26, p 78) and ensures that there is a single agreed-upon correct answer to each multiple-choice item and that all distractors are incorrect. ${ }^{27}$ In our experience, expert validation also promotes further improvements in the assessment instruments and helps maintain consensus within the department when interested faculty are involved in the validation process. For example, a series of questions were designed to assess student understanding of why multiple titration runs are completed and their value in estimating uncertainty versus accuracy of the results. However, following expert validation, the level of technical jargon required to express these concepts accurately became painfully apparent, accompanied by realization that such terminology was beyond the scope of the first-year course. The ensuing discussion ultimately revealed that the course instructor was more concerned about students' abilities to diagnose anomalous titration outcomes. This realization resulted in an entirely new set of assessment items that not only better addressed course goals, but also provided written assessment of students' troubleshooting knowledge. Assessment of troubleshooting was previously limited to evidence found in notebook records (which would only be apparent if a student encountered the difficulties of interest) and to direct observation of students completing the laboratory activity. Changes were also made to the laboratory manual to reduce jargon in discussions of repeating titrations and the related LG simply directs students to "describe the purpose and value of repeating tests (such as titrations)".

Next, LG assessments were validated with students to identify wording that they interpret correctly and to prevent selection of the correct response for wrong reasons or vice versa, further improving face validity. This requires interviewing students from the target population. These interviews were accomplished by soliciting volunteers from the course (via email) and providing a small monetary incentive (\$15 CAD) for participation. Interested students provided relevant demographic and grade data when they volunteered. These data were used to select a stratified sample from the volunteer pool so that the breadth of the population can be captured in the interviews. The total number of interviewees needed depends mainly on reaching the point at which the interviewer decided that no new information was being obtained. ${ }^{28}$ Our experience has shown that this may occur after as few as six interviews. Additionally, changes were made to intended assessment items whenever a clear misinterpretation or apparent confusion with an assessment item was identified so that fully improved assessment items were used during each interview. Validation interviews were conducted one-on-one with students, and audio-recorded for future reference and verification of interview notes. A think-aloud technique ${ }^{29}$ was employed, so that the interviewer did not interfere with or influence student responses. If the student stopped speaking, the interviewer used only nondirective prompts such as "What are you thinking?" but never asked the student to explain until after they have completed working through the questions, as the act of explaining to another may alter the thought process. ${ }^{30}$

Following is an example of improvements arising from student validations of multiple-choice and true-false items based on open-ended questions and observations of students completing the titration process. From the first round of data collection, it was noted that some students believed that a titration with a color-change endpoint would necessarily remain colored "permanently", resulting in development of this question:

You are doing a titration with an indicator that turns pink at the endpoint. A light pink color has now remained for $\sim 15$ seconds with stirring.

$\mathrm{T}$ or F: The solution must remain permanently colored to indicate the endpoint. 
However, student validation interviews showed that the truefalse statement was not being interpreted consistently and some students with correct reasoning would answer incorrectly. Further discussion of validation results and the finer points of titration led the team to further refine the item to:

You are doing a titration with phenolphthalein, an indicator that turns pink at the endpoint. A light pink color has now remained for 5-10 seconds with stirring. $\mathrm{T}$ or F: A student's solution remained pink for 20 seconds, but 1 minute later their solution was colorless. This means the endpoint was NOT reached.

Additionally, student interviews may also reveal previously undetected and unreported misconceptions, as the think-aloud method provides unique insight into student thinking. ${ }^{30}$ For example, as students verbalized their thoughts while considering questions about liquid-liquid extraction, researchers noted a misconception that density alone could be used to decide whether two liquids were miscible. Results from the first round of question development suggest that $>45 \%$ of students in our first-year chemistry laboratory course hold this misconception; however, questions designed to assess this misconception require further refinement. During these interviews, our undergraduate researchers also identified a student misconception that appears to increase during their introductory chemistry course. Previously, our data indicated the concept that a melting point decreases when impurities are present was well understood. However when a multiple-choice option was added (due to validation interview results in Year 3 of the project) describing the melting point as decreasing or increasing from impurities, a different conclusion was warranted. See Table 2.

Table 2. Prelab and Postlab Test Results Concerning Impure Crystal Melting Point

\begin{tabular}{ccc} 
Year $(n)$ & $\begin{array}{c}\text { Correct Prelab } \\
\text { Responses, \% }\end{array}$ & $\begin{array}{c}\text { Correct Postlab } \\
\text { Responses, \% }\end{array}$ \\
Year 1 (539) & 53 & 93 \\
Year 2 (181) & 60 & 80 \\
Year 3 (242): Increase or & 76 & 40 \\
decrease option added & & \\
\hline
\end{tabular}

Again, the importance of validation interviews with students cannot be overemphasized, as they (i) support face validity; (ii) ensure students interpret the assessment items as intended and arrive at a correct answer with correct thinking; and (iii) reveal student reasoning. (Note: Student interviews may require obtaining prior institutional approval, depending on the intentions to publish the results and the institution's humansubject research ethics protocols.)

\section{“EXPERIMENTAL" DESIGN}

To assess what students have gained from a learning situation, such as a laboratory activity, it can be argued that one should first assess what students know prior to the event (pretest) and afterward (posttest). Additionally, it will take time to produce assessments that are ready to be part of the regular course. However, significant levels of student participation may be needed to obtain a sufficient amount of data to perform statistics and convince faculty members of the assessment's value. Thankfully, the majority of students in the course participated voluntarily in return for very small bonus-point incentives and the explicit knowledge that their participation will aid in course improvements. A best-case scenario would have these assessments be made a normal part of class participation, separate from graded assessments.

\section{ALIGNMENT OF COURSE WITH LEARNING GOALS}

After LGs have been developed, the laboratory activities that students are required to complete and materials used to evaluate their course success were examined for alignment with the LGs. Disconnects were discovered. These disconnects suggested a range of actions, from considerable reworking of course materials to simple realignment of the grading scheme to better focus on important goals. For example, proper maintenance of a laboratory notebook was identified as a priority LG for the first-year laboratory course. However, examination of the grading scheme revealed that only a few points were allocated to this task while considerably more points were assigned to the experimental report (a higher-level goal that the team decided was more appropriate for later in the curriculum). Thus, points were reallocated from the report itself to the laboratory notebook. In the following year, a module on making observations and peer marking of laboratory observations was also added (see the Supporting Information for more details). Analysis of 68 student laboratory notebooks sampled from each of the past three years indicates improvements in certain skills, such as the recording of observations, as documented in Table 3. Plausibly, the improvements from

Table 3. Average Correctness of Student Laboratory Notebook Observations

$\begin{array}{cccc}\text { Year }(n) & \begin{array}{c}\text { Scoring Changes } \\ \text { Average Points } \\ \text { per Lab }{ }^{a} \text { for Lab } \\ \text { Notebook, \% }\end{array} & \begin{array}{c}\text { Average } \\ \text { Observation }\end{array} \\ \text { Correctness } \\ \text { "Score", \% }\end{array}$

${ }^{a}$ Percent points per lab are given as an approximate owing to slight differences in each activity's scoring. ${ }^{b}$ Observation module and an example of a peer-marking guide are provided in the Supporting Information. "Correctness "score" based on presence of several different activity-appropriate observations.

Year 1 to Year 2 may partially be attributed to the clarity of LG statements and reallocation of points, which presumably suggested to students that the notebook was a valued part of laboratory grading. In Year 3, by incorporating peer evaluation and a brief module during laboratory check-in, this improvement again doubled, with minimal increase in instructor or TA workload.

\section{USING SURVEYS AS COURSE ASSESSMENTS}

As noted previously, the time and effort associated with this process ultimately enables one to evaluate the success of a course, as opposed to individual student success. However, these assessment results could be compromised if students sense a need to "give the right answer" rather than responding honestly; thus, we recommend administering these assessments apart from tasks to establish student grades. When results of such tests do not count toward a student's grade, "they have no incentive to take the time required to search out the answers 
and memorize them". ${ }^{27}$ In the absence of a grade incentive to regard the assessment as a serious endeavor, however, one must provide suitable inducements to evoke sincere effort. We have found that providing a very small bonus point allowance for completing the test, explicit knowledge that test results will be used to improve the course, and a final question where students indicate how seriously they regarded the test (shown below in Figure 3) resulted in considerable levels of serious participation

\section{How seriously did you take this survey? (Please answer honestly; you will get the bonus point anyway.) \\ a. I did not take the survey seriously and/or did not think about a lot of the answers. \\ b. I took it sort of seriously but when I did not know an answer I did not think very hard about it. \\ c. I took it seriously but when I did not recognize something, I guessed. \\ d. I took it seriously and thought about my answers.}

Figure 3. "Seriousness" question given at the end of each assessment. (Note: Any response other than "a" was regarded as serious. Additionally, because the assessments were administered alongside normal laboratory quizzes, we called them surveys to avoid confusion.)

and adequate controls to minimize frivolous responses. With data provided by the process and these course assessments, we have

Cultivated departmental consensus regarding what students should learn in the course

Provided students with clear descriptions of what they should learn (LGs)

Emphasized basic and transferable skill development (such as suitable notebook maintenance and correct volumetric glassware manipulation) through enhanced assessment of these skills

Better aligned course grading policies with identified LGs Better aligned instructional materials and TA orientation with established LGs

Provided credible feedback regarding student attainment of LGs to target course improvements for optimizing instructional use of limited laboratory contact hours

\section{SUMMARY OF THE PROCESS}

The potentially challenging task of identifying learning goals or performance objectives for an introductory science laboratory course can be accomplished systematically and productively. To begin, resolve to deal with inherent challenges: start with current laboratory instructional materials, identify an overarching theme or focus for the course, and engage invested parties throughout the process. Next, build initial LGs around an existing framework. ${ }^{23}$ If possible, engage an experienced person in discipline-based educational research to help in LG synthesis, alignment with course goals, employing clear, operational language, and organizing the resulting LGs into the agreed-upon framework. With iteratively refined LGs identified, re-examine current laboratory materials to avoid duplicating existing assessments and prioritize remaining LGs to focus assessment-development efforts. Decide on the best way to assess particular learning goals or types of learning goals, compare this to assessments currently used in the course, and develop new assessments to fill the gaps. Validate these assessments with experts (to enhance consensus, construct validity, and face validity) and students (to ensure assessments are correctly interpreted and further support face validity). Administer the assessments using a pretest-posttest strategy to assess the impact of new goal-centered course improvements. Finally, ensure that current student assessments are aligned with the LGs and make any needed adjustments.

\section{DISCUSSION}

Several insights were gained through this process. The detailed listing of LGs forced acknowledgment of overloaded learning expectations in the course and highlighted the need for their prioritization. Validation is absolutely essential for development of useful, impactful assessment instruments. When dealing with a broadly based introductory course, in particular, input from outside experts to supplement areas of expertise already represented on the development team is particularly useful and ultimately can improve the LGs and corresponding assessments. Even more important, however, is validation with the student population of interest. These interviews permit one to understand how students interpret the questions and how they go about answering them. This not only allows problems with the assessments to be identified and fixed, more importantly, it allows appropriate conclusions to be drawn from students' responses. In addition, the Interdisciplinary Teaching Laboratory Learning Objectives developed at Rice University ${ }^{23}$ are expressed at a program level, thus this framework can be applied to each year of a laboratory program, while the use of a committee (including, for example, laboratory instructors and representatives from each subdiscipline within the department) creates a focused opportunity for discussion and consensus building among course stakeholders. Also, because the Rice LGs are interdisciplinary, they can serve as a useful framework applicable across science departments. Finally, the alignment of learning goals and assessments should be checked to ensure students are being tested on the stated objectives of the course. Ultimately, educators are enabled to make decisions based on data, with conclusions drawn from evidence-rather than anecdote-based opinions - to energize and inform meaningful, productive discussions about curricular improvements. While a full discussion of how the optimization of the introductory chemistry laboratory course at UBC has resulted in improvements is beyond the scope of this paper, evidence suggests that this work has brought about positive changes. For example, we have seen marked improvements in students' laboratory notebook observations and students are overwhelmingly positive toward the clearly expressed learning goals now provided for each laboratory experiment.

\section{ASSOCIATED CONTENT}

\section{Supporting Information}

TA guide for the Observation Module; form that students use to complete the observation exercise. This material is available via the Internet at http://pubs.acs.org.

\section{AUTHOR INFORMATION}

\section{Corresponding Author}

*E-mail: Jennifer.Duis@nau.edu.

\section{Notes}

The authors declare no competing financial interest. 
${ }^{\S}$ Research conducted while at the University of British Columbia, Department of Chemistry, Carl Wieman Science Education Initiative, Vancouver, BC Canada.

\section{ACKNOWLEDGMENTS}

We thank the student participants, expert validators, undergraduate researchers (Mike Carlson, Yuri Samozvanov, Alicia Wong, Y.C. Ainge Chang, Aalia Sachendina, James Zhou, Nicholas Mah, and Samantha D'Souza), UBC Department of Chemistry and Laboratory Committee, Carl Wieman Science Education Initiative (CWSEI) Science Teaching and Learning Fellows, CWSEI funding, Sarah Gilbert, Carl Wieman, Dave Pushkin, and Henry Heikkinen.

\section{REFERENCES}

(1) Melton, R. F. Resolution of Conflicting Claims Concerning the Effect of Behavioral Objectives on Student Learning. Rev. Educ. Res. 1978, 48 (2), 291-302.

(2) Goldsmid, C. A. Why Formalize the Aims of Instruction? [Knowledge Available, Knowledge Needed: Improving Sociology Instruction]. Teach. Sociol. 1981, 8 (3), 263-289.

(3) Raghubir, K. P. The Effects of Prior Knowledge of Learning Outcomes on Student Achievement and Retention in Science Education. J. Res. Sci. Teach. 1979, 16 (4), 301-304.

(4) Chappuis, S.; Stiggins, R. J. Classroom Assessment for Learning. Educ. Leadership 2002, 60 (1), 40-43.

(5) Halonen, J. S.; Appleby, D. C.; Brewer, C. L.; Buskist, W.; Gillem, A. R.; Halpern, D.; Hill, G. W., IV; Lloyd, M. A.; Rudmann, J. L.; Whitlow, V. M.; Beins, B.; Braswell, M. The Assessment Cyberguide for Learning Goals and Outcomes in the Undergraduate Psychology Major; Task Force on Undergraduate Psychology Major Competencies, Board of Educational Affairs, American Psychological Association: Washington, DC, 2002.

(6) Council for Higher Education Accreditation . Statement of Mutual Responsibilities for Student Learning Outcomes: Accreditation, Institutions, and Programs; Institute for Research and StudyAccreditation and Quality Assurance, Council for Higher Education Accreditation: Washington, DC, 2003,; p 6.

(7) Adam, S. Using Learning Outcomes: A Consideration of the Nature, Role, Application and Implications for European Education of Employing "Learning Outcomes" at the Local, National and International Levels; United Kingdom Bologna Seminar, Heriot-Watt University: Edinburgh, Scotland, 2004.

(8) Marsh, P. A. What Is Known about Student Learning Outcomes and How Does It Relate to the Scholarship of Teaching and Learning? Int. J. Scholarship Teach. Learn. 2007, 1 (2), 13.

(9) Mager, R. F. Preparing Instructional Objectives, 3rd ed.; CEP Press: Atlanta, GA, 1997.

(10) Dick, W.; Carey, L.; Carey, J. O. The Systematic Design of Instruction, 7th ed.; Pearson: Upper Saddle River, NJ, 2009.

(11) Towns, M. H. Developing Learning Objectives and Assessment Plans at a Variety of Institutions: Examples and Case Studies. J. Chem. Educ. 2010, 87 (1), 91-96.

(12) Wieman, C.; Perkins, K.; Gilbert, S. Transforming Science Education at Large Research Universities: A Case Study in Progress. Change 2010, 42 (2), 7-14.

(13) Hartely, J.; Davies, I. K. Preinstructional Strategies: The Role of Pretests, Behavioral Objectives, Overviews and Advance Organizers. Rev. Educ. Res. 1976, 46 (2), 239-265.

(14) Johnstone, A. H.; Wham, A. J. B. The Demands of Practical Work. Educ. Chem. 1982, 19 (3), 71-73.

(15) Rice University Natural Sciences and Engineering Laboratory Educators. Detailed list of program-wide teaching and learning objectives, 2006. http://www.owlnet.rice.edu/ labgroup/assessment/ expanded_objectives.html (accessed Jul 2013).
(16) Fink, L. D. Creating Significant Learning Experiences: An Integrated Approach to Designing College Courses, Jossey-Bass: San Francisco, CA, 2003.

(17) Wiggins, G.; McTighe, J. Understanding by Design; Association for Supervision and Curriculum Development: Alexandria, VA, 1998.

(18) Jenkins, J. R.; Neisworth, J. T. The Facilitative Influence of Instructional Objectives. J. Educ. Res. 1973, 66, 254-256.

(19) Simon, B.; Taylor, J. What Is the Value of Course-Specific Learning Goals? J. Coll. Sci. Teach. 2009, 39, 52-57.

(20) Crowe, A.; Dirks, C.; Wenderoth, M. P. Biology in Bloom: Implementing Bloom's Taxonomy To Enhance Student Learning in Biology. CBE Life Sci. Educ. 2008, 7, 368-381.

(21) Nussbaum, S.; Lomas, C.; Nakonechny, J. In Proceedings of the 225th ACS National Meeting, American Chemical Society, New Orleans, LA, March 23-27, 2003.

(22) Saterbak, A.; Beason, B.; Cox, K.; Bordeaux, J.; Caprette, D. In Proceedings of the American Society of Engineering Education Annual Conference and Exposition, Salt Lake City, Utah, June 20-23, 2004.

(23) Rice University Natural Sciences and Engineering Laboratory Educators. Interdisciplinary Web-Based Teaching Laboratory Materials, 2003. http://www.owlnet.rice.edu/ labgroup/index.htm (accessed Jul 2013).

(24) Porter, S. R.; Whitcomb, M. E.; Weitzer, W. H. Multiple Surveys of Students and Survey Fatigue. New Dir. Institutional Res. 2004, 2004 (121), 63-73, DOI: 10.1002/ir.101.

(25) Cooper, M. M.; Sandi-Urena, S. Design and Validation of an Instrument To Assess Metacognitive Skillfulness in Chemistry Problem Solving. J. Chem. Educ. 2009, 86 (2), 240-245.

(26) Slavin, R. E. Research Methods in Education, 2nd ed.; Allyn and Bacon: Needham Heights, MA, 1992; p 78.

(27) Adams, W. K.; Wieman, C. E. Development and Validation of Instruments to Measure Learning of Expert-Like Thinking. Int. J. Sci. Educ. 2011, 33 (9), 1289-1312, DOI: 10.1080/ 09500693.2010.512369.

(28) Guest, G.; Bunce, A.; Johnson, L. How Many Interviews Are Enough?: An Experiment with Data Saturation and Variability. Field Methods 2006, 18 (1), 59-82.

(29) Ericsson, K. A.; Simon, H. A. How To Study Thinking in Everyday Life: Contrasting Think-Aloud Protocols with Descriptions and Explanations of Thinking. Mind, Cult., Act. 1998, 5 (3), 178-186.

(30) Berardi-Coletta, B.; Buyer, L. S.; Dominowski, R. L.; Rellinger, E. R. Metacognition and Problem Solving: A Process-Oriented Approach. J. Exp. Psychol.: Learn., Mem. Cogn. 1995, 21 (1), 205-223. 